\title{
Cerium oxide nanoparticles protect rodent lungs from hypobaric hypoxia-induced oxidative stress and inflammation
}

This article was published in the following Dove Press journal:

International Journal of Nanomedicine

20 November 2013

Number of times this article has been viewed

\section{Aditya Arya' \\ Niroj Kumar Sethy' \\ Sushil Kumar Singh ${ }^{2}$ \\ Mainak Das ${ }^{3}$ \\ Kalpana Bhargava'}

'Peptide and Proteomics Division, Defence Institute of Physiology and Allied Sciences, Defence Research and Development Organization, Delhi, ${ }^{2}$ Functional Materials Division, Solid State Physics Laboratory, Defence Research and Development Organization, Delhi, ${ }^{3}$ Biological Science and Bioengineering, Indian Institute of Technology, Kanpur, Uttar Pradesh, India
Correspondence: Kalpana Bhargava Peptide and Proteomics Division, Defence Institute of Physiology and Allied Sciences, Defence Research and Development Organization, Lucknow Road, Timarpur, Delhi, India

$\mathrm{Tel}+9$ | I | 23883010

Fax+9| II 23932869

Email kalpanab@dipas.drdo.in

Niroj Kumar Sethy

Peptide and Proteomics Division, Defence Institute of Physiology and Allied Sciences, Defence Research and Development Organization, Lucknow Road, Timarpur, Delhi, India

Tel +9 I I I 23883003

Fax +9| || 23932869

Email nksethy@gmail.com
Background: Cerium oxide nanoparticles (nanoceria) are effective at quenching reactive oxygen species (ROS) in cell culture and animal models. Although nanoceria reportedly deposit in lungs, their efficacy in conferring lung protection during oxidative stress remains unexplored. Thus, the study evaluated the protective efficacy of nanoceria in rat lung tissue during hypobaric hypoxia.

Methods: A total of 48 animals were randomly divided into four equal groups (control [C], nanoceria treated $[\mathrm{T}]$, hypoxia $[\mathrm{H}]$, and nanoceria treated plus hypoxia $[\mathrm{T}+\mathrm{H}]$ ). Animals were injected intraperitoneally with either a dose of $0.5 \mu \mathrm{g} / \mathrm{kg}$ body weight/week of nanoceria ( $\mathrm{T}$ and $\mathrm{T}+\mathrm{H}$ groups) or vehicle ( $\mathrm{C}$ and $\mathrm{H}$ groups) for 5 weeks. After the final dose, $\mathrm{H}$ and $\mathrm{T}+\mathrm{H}$ animals were challenged with hypobaric hypoxia, while $\mathrm{C}$ and $\mathrm{T}$ animals were maintained at normoxia. Lungs were isolated and homogenate was obtained for analysis of ROS, lipid peroxidation, glutathione, protein carbonylation, and 4-hydroxynonenal-adduct formation. Plasma was used for estimating major inflammatory cytokines using enzyme-linked immunosorbent assay. Intact lung tissues were fixed and both transmission electron microscopy and histopathological examinations were carried out separately for detecting internalization of nanoparticles as well as altered lung morphology.

Results: Spherical nanoceria of 7-10 nm diameter were synthesized using a microemulsion method, and the lung protective efficacy of the nanoceria evaluated during hypobaric hypoxia. With repeated intraperitoneal injections of low micromole concentration, we successfully localized the nanoceria in rodent lung without any inflammatory response. The lung-deposited nanoceria limited ROS formation, lipid peroxidation, and glutathione oxidation, and prevented oxidative protein modifications like nitration and carbonyl formation during hypobaric hypoxia. We also observed reduced lung inflammation in the nanoceria-injected lungs, supporting the anti-inflammatory properties of nanoceria.

Conclusion: Cumulatively, these results suggest nanoceria deposit in lungs, confer protection by quenching noxious free radicals during hypobaric hypoxia, and do not evoke any inflammatory response.

Keywords: nanoceria, high altitude, nanomedicine

\section{Introduction}

The therapeutic applications of cerium oxide nanoparticles (nanoceria) have gained recent attention. Nanoceria have the unique ability to switch between cerium (III) and cerium (IV) oxidation states depending on the physiological environment. This self-regeneration, along with oxygen defects in their crystal lattice structure, enables nanoceria to scavenge superoxide, hydrogen peroxide, and hydroxyl and nitric oxide radicals. ${ }^{1}$ Depending on surface oxidation state, nanoceria mimic the activities of 
the cellular antioxidant enzymes superoxide dismutase and catalase. $^{2,3}$ These particles are noncytotoxic, retained in the body, localized in tissue, ${ }^{4-6}$ and reportedly protect cells ${ }^{7-9}$ and animal models from chemical, ${ }^{10,11}$ radiological, ${ }^{12,13}$ and biological oxidative stress. ${ }^{14,15}$ Apart from intracellular freeradical quenching, nanoceria also promote angiogenesis ${ }^{8}$ and wound healing, ${ }^{16}$ improve the life span of photoreceptor cells, ${ }^{17}$ and reduce chronic inflammation. ${ }^{18}$

Conditions of physiological and pathological hypoxia affect lung function and subsequent oxygenation in organisms. ${ }^{19-21}$ These oxygen-limiting conditions favor the enhanced formation of reactive oxygen and nitrogen species (RONS) by mitochondria electron transport chains, nicotinamide adenine dinucleotide phosphate (NADPH) oxidase, xanthine oxidase/reductase, and nitric oxide synthase enzymes, as well as establishing an inflammatory process. ${ }^{22-24}$ The concomitant depletion of cellular enzymatic and nonenzymatic antioxidant substrates from lungs also favors RONS formation. ${ }^{25}$ This hypoxia-induced redox imbalance is a primary factor for lung pathological processes such as an increase of pulmonary artery pressure, epithelial malfunction, edema, and inflammation in acute form. Similarly, chronic hypoxia exposure results in vascular proliferation, an increase in vascular reactivity, chronic pulmonary hypertension, and right heart failure..$^{20,21,26-28}$ Thus, it has been advocated that supplementation with suitable antioxidants may minimize the ill effects of hypoxia on the lungs. ${ }^{29-31}$

The pharmacological potential of nanoceria for lung protection against oxidative stress has been poorly evaluated. Organ deposition, persistence, and subsequent biological activities depend on the size, shape, charge, dosage, and method of administration of nanoceria. ${ }^{4-6}$ As such, we evaluated the lung localization and antioxidant potential of spherical nanoceria with a diameter of $7-10 \mathrm{~nm}$ after repeated intraperitoneal (ip) injections in rats. Our results suggest that intraperitoneally injected nanoceria localize in the lung, do not evoke any inflammatory response, and confer protection against hypoxia-induced oxidative stress.

\section{Methods}

\section{Synthesis and characterization of nanoceria}

Cerium oxide nanoparticles were synthesized from aqueous solutions of cerium (III) nitrate and hexamethylenetetramine (HMTA; 99.999\% pure; Sigma-Aldrich, St Louis, MO, USA) using a microemulsion method. ${ }^{32}$ In brief, $20 \mathrm{~mL} 0.0125 \mathrm{M}$ cerium (III) nitrate was added dropwise to $200 \mathrm{~mL} 0.0125 \mathrm{M}$ HMTA under continuous stirring for 0.5 hours. The mixture was heated at $80^{\circ} \mathrm{C}$ and continuously stirred until a white colloid suspension formed. The nanoceria were separated from the suspension by centrifugation at $1500 \mathrm{~g}$ for $30 \mathrm{~min}$ utes, washed with deionized water then acetone, and this was followed by vacuum drying.

The particle size and morphology of the nanoceria were determined by phase-contrast high-resolution transmission electron microscopy (HR-TEM) using a Philips Tecnai G230 transmission electron microscope (Amsterdam, the Netherlands) operating at an accelerating voltage of $300 \mathrm{kV}$ and equipped with energy dispersive spectrometry. Selectedarea electron diffraction (SAED) was also performed to confirm the crystal structure. X-ray diffraction patterns were measured with a Bruker D8 Advance (Billerica, MA, USA) and Rigaku MiniFlex II X-ray diffractometer (Tokyo, Japan) employing monochromatized $\mathrm{CuK} \alpha$ radiation $(\lambda=1.54056 \AA)$ at $298 \mathrm{~K}$. Zeta potential and relative hydrodynamic radius were estimated using dynamic light scattering on a Nano$\operatorname{trac}^{\mathrm{TM}}$ (Microtrac, Montgomeryville, PA, USA).

\section{Experimental animals and hypoxia exposure}

Male Sprague Dawley rats weighing 180-200 g were used in this study. The rats were housed in the experimental animal facility of the Defence Institute of Physiology and Allied Sciences and received standard diet and reverse osmosis water ad libitum.

For hypobaric hypoxia exposure, animals were exposed to an altitude of 25,000 feet $(7,620 \mathrm{~m}, 282 \mathrm{mmHg})$ for 3 hours. Both the rate of ascent to altitude and descent to sea level were maintained at $300 \mathrm{~m} /$ minute, while the temperature and humidity of the chamber were maintained at $28^{\circ} \mathrm{C}$ and $60 \% \pm 5 \%$, respectively. A continuous airflow of $8 \mathrm{~L} /$ minute was maintained in the chamber during the period of exposure.

All study animal care and experimental protocols were approved by the Animal Ethical Committee of Defence Institute of Physiology and Allied Sciences under supervision of the Indian Ministry of Environment and Forest's Committee for the Purpose of Control and Supervision of Experiments on Animals.

\section{Optimization of dose and duration of dosage}

A homogenous suspension of nanoceria in phosphatebuffered saline (PBS; pH 7.4) was intraperitoneally injected into rats ( $\mathrm{n}=10$ rats per group) with $0.1,0.5,10.0$, or 100.0 $\mu \mathrm{g} / \mathrm{kg}$ body weight ( $\mathrm{bw}$ )/week for 5 consecutive weeks while 
control rats received only PBS. After 24 hours following the final injection, all the rats were exposed to hypobaric hypoxia. Blood samples and lung tissue samples were collected and used to find the minimum effective dose by estimating the plasma and lung content of malonaldehyde (MDA) and free radicals (ROS). The same plasma samples were also used for estimation of proinflammatory interleukin (IL)-1 $\beta$, IL-6, and tumor necrosis factor alpha (TNF- $\alpha$ ) cytokine levels.

In the second part of the study, the minimum effective dose of nanoceria was injected into animals $(n=10$ in each group, once per week ip injection) for 2, 3, 5, or 7 weeks, while the control group received vehicle. The animals were exposed to hypobaric hypoxia and plasma, and their lung MDA and ROS contents were measured to find out the effective dosage duration for the nanoceria injection. For each duration, plasma levels of proinflammatory IL-1 $\beta$, IL-6, and TNF- $\alpha$ cytokines were also measured.

In the third part of the study, 48 animals were randomly divided into four equal groups (control [C], nanoceria treated $[\mathrm{T}]$, hypoxia $[\mathrm{H}]$, and nanoceria treated plus hypoxia $[\mathrm{T}+\mathrm{H}])$. Animals were injected intraperitoneally with a dose of $0.5 \mu \mathrm{g} / \mathrm{kg}$ bw/week of nanoceria ( $\mathrm{T}$ and $\mathrm{T}+\mathrm{H}$ groups) or vehicle ( $\mathrm{C}$ and $\mathrm{H}$ groups) for 5 weeks. ${ }^{6,32}$ After the final dose, animals in the $\mathrm{H}$ and $\mathrm{T}+\mathrm{H}$ groups were challenged with hypobaric hypoxia as described earlier, while animals in the $\mathrm{C}$ and $\mathrm{T}$ groups were maintained at normoxia. After exposure, all the animals were sacrificed using sodium pentobarbital and blood and lung samples were taken for use in further studies.

\section{Electron microscopy of lung tissue}

Animals were fixed with $2 \%$ paraformaldehyde and lung tissues were collected. Tissues were sectioned into $1 \times 1 \mathrm{~mm}$ pieces and allowed to fix overnight before being embedded in araldite resin, cut into $2 \mathrm{~nm}$ thick sections using a Leica EM UC7 Ultramicrotome (Leica Microsystems GmbH, Wetzlar, Germany) and fixed on copper grids. Grids were analyzed under transmission electron microscope (Tecnai G2 Spirit, FEI Company, Hillsboro, OR, USA) at a power of $120 \mathrm{keV}$ and $15 \mathrm{~K}$ magnification. Images were acquired and analyzed using Tecnai EPU automation software, version 2.0. The presence of nanoceria was further confirmed with SAED. A minimum of two grids per sample were analyzed with five different fields.

\section{Estimation of inflammatory cytokines}

Inflammatory cytokines IL- $1 \beta$, IL- 6 , and TNF- $\alpha$ were estimated in plasma using enzyme-linked immunosorbent assay (ELISA) kits (RayBiotech, Norcross, GA, USA) as per the manufacturer's instructions. Briefly, IL standards were prepared by diluting with assay buffer. Plasma samples or standards were added to an ELISA plate and incubated for 2 hours at room temperature on a rocking platform. The plate was then washed twice with wash buffer and anti-cytokine antibody added before incubating for another 2 hours. Following this, the plate was washed twice and incubated with streptavidin for 1 hour. Finally, the plate was washed and substrate was added to each well and incubated until color developed. At this point, the reaction was stopped using stopping solution and the optical density at $450 \mathrm{~nm}$ was measured using a spectrophotometer (Spectramax M2, Molecular Devices, Sunnyvale, CA, USA).

\section{Histological examination of lung tissue}

Lung tissue from all the groups was fixed in formalin, dehydrated through serial concentrations of ethanol, cleared in xylene, and embedded in paraffin wax. Sections were cut at $5 \mu \mathrm{m}$ thickness and stained with hematoxylin and eosin. The slides were observed under optical microscope at 20× magnification (BX51, Olympus Corporation, Tokyo, Japan). A minimum of three random sections per slide and at least three different fields were assessed for histopathological conditions. All slides were evaluated by a veterinary pathologist in a blinded manner.

\section{Estimation of oxidative stress parameters ROS estimation}

ROS levels were measured with a nonfluorescent lipophilic dye, Dichlorofluorescein diacetate, which passively diffuses through cellular membranes, is cleaved into 2,7-dichlorofluorescein by intracellular esterase enzymes in the presence of intracellular ROS, and produces fluorescence. The fluorescence is known to be directly proportional to the ROS levels. ${ }^{33}$ Ten microliters of $10 \mu \mathrm{M}$ Dichlorofluorescein diacetate was added to $150 \mu \mathrm{L}$ of lung tissue homogenate $(10 \% \mathrm{w} / \mathrm{v}$ in RIPA [radio immunoprecipitation assay] buffer, Thermo Fisher Scientific, Waltham, MA, USA) and incubated for 40 minutes at $37^{\circ} \mathrm{C}$ in amber tubes (Borosil, West Orange, NJ, USA) in the dark. Fluorescence was measured at $488 \mathrm{~nm}$ excitation and $525 \mathrm{~nm}$ emission (LS 45 Luminescence Spectrometer, PerkinElmer, Waltham, MA, USA) and converted to AU/ $\mathrm{mg}$ of protein.

\section{Estimation of lipid peroxidation}

Lipid peroxidation was measured by direct estimation of MDA in the tissue homogenate using the method suggested 
by Ohkawa et al with slight modification. ${ }^{34}$ Briefly, $750 \mu \mathrm{L}$ of trichloroacetic acid (TCA; 20\% in distilled water) and $750 \mu \mathrm{L}$ of thiobarbituric acid $(0.67 \%$ in $0.05 \mathrm{M} \mathrm{NaOH})$ were added to $250 \mu \mathrm{L}$ of the lung tissue homogenate. The mixtures were incubated in a water bath at $85^{\circ} \mathrm{C}$ for 45 minutes then allowed to cool at room temperature before being centrifuged at $400 \mathrm{~g}$ for 5 minutes. About $200 \mu \mathrm{L}$ of the supernatant was removed and the absorbance was measured at $531 \mathrm{~nm}$ using a spectrophotometer (VersaMax ELISA Microplate Reader, Molecular Devices, Sunnyvale, CA, USA). The values are expressed in $\mu \mathrm{mol} / \mathrm{mg}$ of protein.

\section{Measurement of antioxidant status}

The ratio of reduced glutathione (GSH) to oxidized GSH (GSSG) was measured in lung tissue homogenate by microplate assay using total a GSH/GSSG assay kit (Oxford Biomedical Research, Rochester Hills, MI, USA) according to the manufacturer's instructions. Briefly, standards were prepared by diluting with assay buffer. Samples were prepared separately for GSH and GSSG, as thiol scavanger was added to the sample for GSSG, but not for GSH. Metaphosphoric acid (5\%) was added to the samples and the mixture centrifuged at $1000 \mathrm{~g}$ for 10 minutes. Following this, $50 \mu \mathrm{L}$ of the supernatant was added to a microtiter plate along with $50 \mu \mathrm{L}$ of 5,5-dithiobis-2-nitrobenzoic acid and $50 \mu \mathrm{L}$ of reductase solution, then the plate was incubated at $30^{\circ} \mathrm{C}$ in an orbital shaker. Finally, $50 \mu \mathrm{L}$ of NADPH was added to each well and absorbance was recorded at $412 \mathrm{~nm}$ at intervals of 1 minute for 10 minutes using an ELISA plate reader. Data was acquired using Gen5 Data Analysis Software version 2.0 (BioTek, Winooski, VT, USA) and represented as the ratio of GSH to GSSG.

\section{Estimation of 4-hydroxynoneal (4-HNE) adduct content}

4-HNE adduct was estimated in lung homogenates using an OxiSelect ${ }^{\mathrm{TM}}$ HNE ELISA Kit (Cell Biolabs, Inc, San Diego, CA, USA) according to the manufacturer's instructions. Briefly, $100 \mu \mathrm{L}$ of lung tissue homogenate or standard HNEBSA (4-hydroxynonenal-bovine serum albumin) adduct were adsorbed onto a 96-well protein-binding plate overnight at $4^{\circ} \mathrm{C}$. After washing with PBS, adducts present in samples or standards were probed with anti-HNE antibody and further incubated for 2 hours at room temperature. Following this, horseradish peroxidase-conjugated secondary antibody was added and the plate incubated for another hour. Finally, chromogenic substrate was added and the plate incubated until color developed, at which point the reaction was stopped using stop solution. Optical density was determined immediately at $450 \mathrm{~nm}$, and the concentration of HNE adduct was calculated from standard curve and expressed as $\mu \mathrm{g}$ of HNE adduct $/ \mathrm{mL}$ of tissue homogenate.

\section{Estimation of protein carbonyl content}

Protein carbonylation assay was performed using a protein carbonyl assay kit (Cayman Chemical Company, Ann Arbor, MI, USA) as per the manufacturer's instructions. Briefly, $200 \mu \mathrm{L}$ of lung tissue homogenate was added with $800 \mu \mathrm{L}$ of 2,4-dinitrophenylhydrazine. A control tube was added with $800 \mu \mathrm{L}$ of $2.5 \mathrm{M}$ hydrochloric acid. Both tubes were incubated in the dark at room temperature for 1 hour. Following this, $1 \mathrm{~mL}$ of $20 \%$ TCA was added to each tube and the tubes incubated on ice for 5 minutes. Tubes were centrifuged at $10,000 \mathrm{~g}$ for 10 minutes at $4^{\circ} \mathrm{C}$ to pellet the protein. The pellet was resuspended in $1 \mathrm{~mL}$ of $10 \%$ TCA and incubated on ice for another 5 minutes. After this, the tubes were centrifuged again at $10,000 \mathrm{~g}$ for 10 minutes before the pellet was washed in a 1:1 mixture of ethanol and ethyl acetate. The pellet was then resuspended in $500 \mu \mathrm{L}$ of guanidine hydrochloride and centrifuged once more at $10,000 \mathrm{~g}$ for 10 minutes. Finally, $220 \mu \mathrm{L}$ of the supernatant from the sample tube and from the control tube was loaded into microtiter plate and absorbance was measured at $370 \mathrm{~nm}$. The carbonyl content was measured using the molar absorption coefficient $22,000 \mathrm{M}^{-1} \mathrm{~cm}^{-1}$ and expressed as $\mathrm{pmol} / \mathrm{mg}$ of protein.

\section{3-Nitrotyrosine (3-NT) estimation}

The frozen lung samples were thawed and homogenized on ice in RIPA Buffer. The homogenates were sonicated three times for 5 seconds each time then centrifuged at 14,000 $\mathrm{g}$ for 20 minutes at $4^{\circ} \mathrm{C}$. The supernatants were used to measure 3-NT concentrations using an OxiSelect ${ }^{\mathrm{TM}}$ Nitrotyrosine ELISA Kit (Cell Biolabs, Inc) according to the manufacturer's protocol. Results were normalized per $\mathrm{mg}$ of protein.

\section{Statistical analysis}

All values are expressed as mean \pm standard error of the mean. The results were analyzed with one-way analysis of variance with Newman-Keuls post-hoc tests using GraphPad Prism software (v 5.0; GraphPad Software, San Diego, CA, USA). Statistical significance was defined as $P<0.05$.

\section{Results}

HR-TEM analysis of nanoceria synthesized by modified microemulsion method revealed that the particles had a 

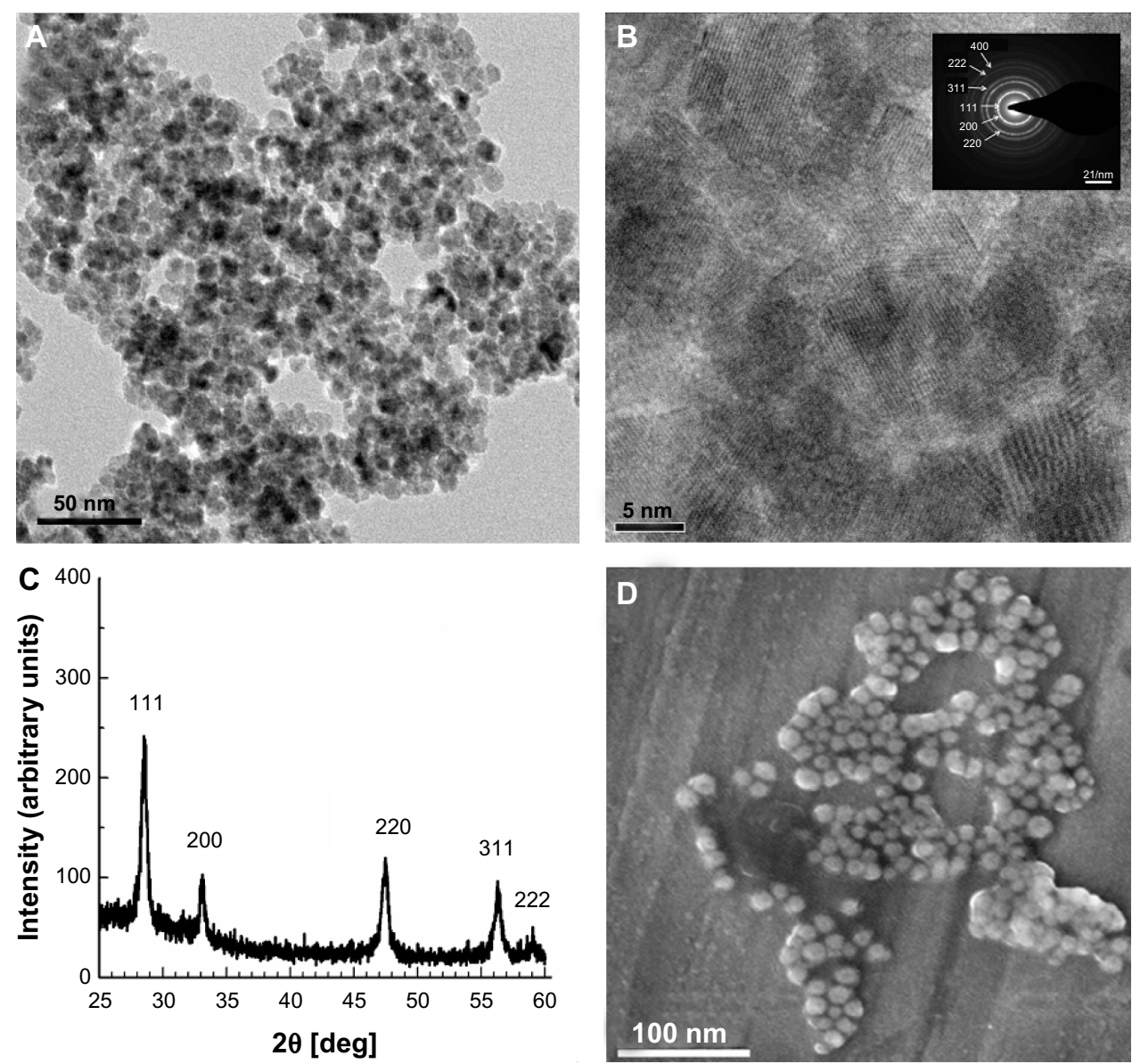

Figure I Characterization of nanoceria. (A) High-resolution transmission electron microscopy (HR-TEM) photomicrograph revealing the spherical shape of nanoceria; the average diameter of each particle was 7-10 nm. (B) HR-TEM micrograph of nanoceria showing the crystalline fringes in particles. (Inset) The selected-area electron diffraction pattern further confirms the crystalline structure of the nanoceria. (C) X-ray diffraction of nanoceria particles showing the characteristic peaks of the crystal. The Miller indices demonstrate the high purity of the synthesized nanoparticles. (D) Scanning electron microscopy analysis showing the spherical shape and homogenous surface topology of the nanoparticles.

spherical morphology (Figure 1A) and were predominantly in the size range of 5-9 nm. Individual crystals with high crystallinity were observed as well-defined lattice fringes (Figure 1B). The SAED (Fig 1B inset) corresponded to the different lattice planes of the fluorite structure. The X-ray diffraction pattern of nanoceria also exhibited a crystalline structure with prominent Miller indices of $\{111\},\{200\}$, $\{220\}$, and $\{311\}$, and when superimposed on the diffraction database, it matched the crystal pattern of $99 \%$ pure nanoceria (Figure 1C). Scanning electron microscopy also revealed spherical morphology and an average particle diameter of 7-10 nm (Figure 1D). Dynamic light scattering measurements showed that the average hydrodynamic diameter of the particles was $110.7 \mathrm{~nm}$ and $283.3 \mathrm{~nm}$, with a zeta potential of $-42.4 \mathrm{mV}$ and $-63.2 \mathrm{mV}$ in deionized water and PBS, respectively, confirming the stability of the nanoceria. The optimally engineered nanoceria were used further in animal studies.
Higher doses of nanoceria ( $\geq 300 \mu \mathrm{g} / \mathrm{kg} \mathrm{bw}$ ) have been reported to be toxic,,$^{35}$ so it was imperative to optimize the dose of nanoceria for maximal antioxidant activity. To determine the minimum effective dose, we intraperitoneally injected uniform nanoceria PBS suspensions at concentrations of $0.1,0.5,10.0$, or $100.0 \mu \mathrm{g} / \mathrm{kg} \mathrm{bw} /$ week into rats for 5 weeks. These repeated doses have been reported to be safe and well below the in vivo toxic levels of nanoceria. ${ }^{5}$ Twenty-four hours after the last dose, we exposed the treated and vehicle control rats to hypobaric hypoxia $(25,000 \mathrm{ft}$, $282 \mathrm{mmHg}$ ) for 3 hours and measured ROS and MDA levels in fresh lung homogenates. We observed aggravated ROS and MDA levels in hypoxic lungs, whereas these levels were significantly lowered in lungs treated with all concentrations of nanoceria. Of the nanoceria doses used, we observed that the dosage of $0.5 \mu \mathrm{g} / \mathrm{kg}$ bw/week exhibited optimal in vivo antioxidant capacity, hence identified this as the minimal effective dose (Figure S1). We also observed similar post- 
hypoxia antioxidant effects of nanoceria in the liver and heart (Figure S2). To optimize the duration of supplementation, we injected the minimum effective dose for 2, 3, 5, or 7 weeks and measured the ROS and MDA levels post-hypoxia insult. Although all the supplementation durations significantly decreased hypoxia-induced ROS and MDA levels, the 5-week supplementation regimen was found to offer the maximum antioxidant effect, suggesting that $0.5 \mu \mathrm{g} / \mathrm{kg}$ bw/week for 5 weeks has the maximal antioxidant effect in hypoxic lungs (Figure S3).

To confirm the availability of nanoceria in the lung, we used transmission electron microscopy for lung sections of 5-week nanoceria-supplemented post-hypoxic rats. We observed the accumulation of nanoceria with particle diameters of 7-10 nm within the lung alveolar cells (Figure 2). We further confirmed the presence of the nanoceria by SAED analysis, which exactly matched the SAED pattern of the supplemented nanoceria.

Next, we determined whether nanoceria injection would evoke any systemic inflammation or aggravate inflammation during hypoxia by measuring the circulating levels of

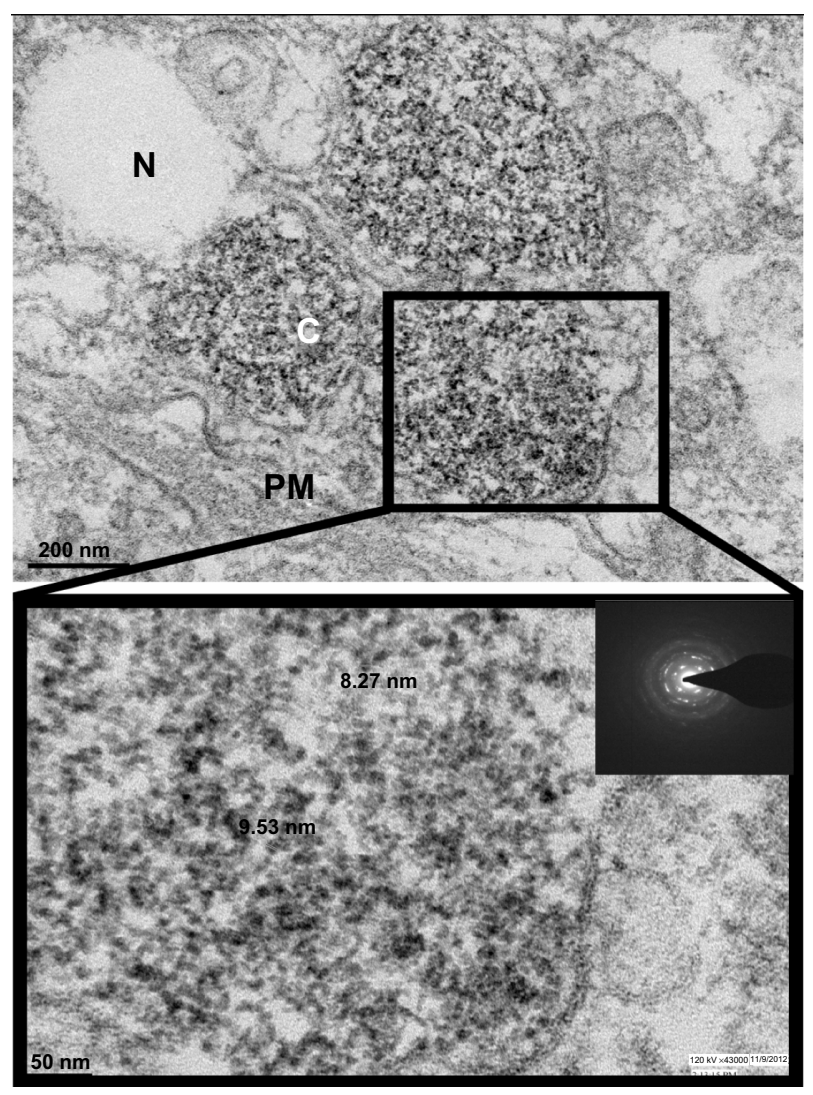

Figure 2 Lung localization of nanoceria. Deposition of electron-dense particles with a size of 7-10 nm in the alveolar spaces. The selected-area electron diffraction pattern (inset) further confirms the presence of nanoceria. Abbreviations: PM, plasma membrane; C, cytoplasm; N, nucleus. proinflammatory cytokines (IL-1 $\beta$, IL-6, and TNF- $\alpha$ ). We observed a 3.00-, 2.13-, and 2.27-fold increase in IL-1 $\beta$, IL-6, and TNF- $\alpha$ levels, respectively, due to hypoxia, while prior nanoceria supplementation significantly prevented this elevation during hypobaric hypoxia (Figure 3). We also checked localized inflammatory responses in the lung using histological analysis. Hematoxylin and eosin-stained lung sections of hypoxia-exposed animals indicated neutrophil infiltration at random alveolar margins, suggesting inflammation induced by hypoxia (Figure 4A). In contrast, we did not find any sign of inflammation in hypoxia-exposed animals previously administered nanoceria, suggesting the anti-inflammatory potential of nanoceria during hypoxia (Figure 4B). These cumulative results suggest that nanoceria supplementation does not evoke any systemic or lung-specific inflammatory response during hypoxia.

Since nanoceria are known to scavenge ROS and hypoxia exposure reportedly induces lung oxidative stress and damage, we measured ROS, MDA, GSH to GSSG ratio, 4-HNE, protein carbonyl, and 3-NT levels in vehicle and nanoceria-supplemented lung homogenates after hypoxia exposure. Levels of ROS and MDA were significantly higher in the lung tissue of hypoxia-exposed animals, whereas nanoceria-supplemented animals exhibited significant lower levels comparable to normoxic levels (Figure 5A and $\mathrm{B}$ ). The GSH to GSSG ratio was reduced by twofold during hypobaric hypoxia, indicating a compromised antioxidant system, while it remained least impaired in animals pretreated with nanoceria (Figure 5C). Further, the lung tissue samples of nanoceria-supplemented animals had HNE-protein adduct levels 83\% lower than hypoxiaexposed animals (Figure 5D). "Protein oxidation" is the covalent modification of a protein induced either directly by ROS or indirectly by its reaction with secondary byproducts. Redox cycling cations such as $\mathrm{Fe}^{2+}$ and $\mathrm{Cu}^{2+}$ can bind to cation-binding locations in proteins and, with the aid of further attack by free radicals, can transform side-chain amino groups of several amino acids into carbonyls. These carbonyl derivatives are chemically stable and serve as markers of oxidative stress. ${ }^{36}$ We found nonsignificant differences in protein carbonyl levels between normoxic and nanoceria-supplemented lungs after hypoxic insult, whereas significantly higher levels were detected in hypoxic lungs, suggesting severe oxidative stress (Figure 5E). Similarly, protein nitration at tyrosine residues caused by peroxynitrite is an oxidative modification and can be detected using anti-3-NT antibodies. The 3-NT content was significantly higher in hypoxia-exposed lungs than in normoxic and 


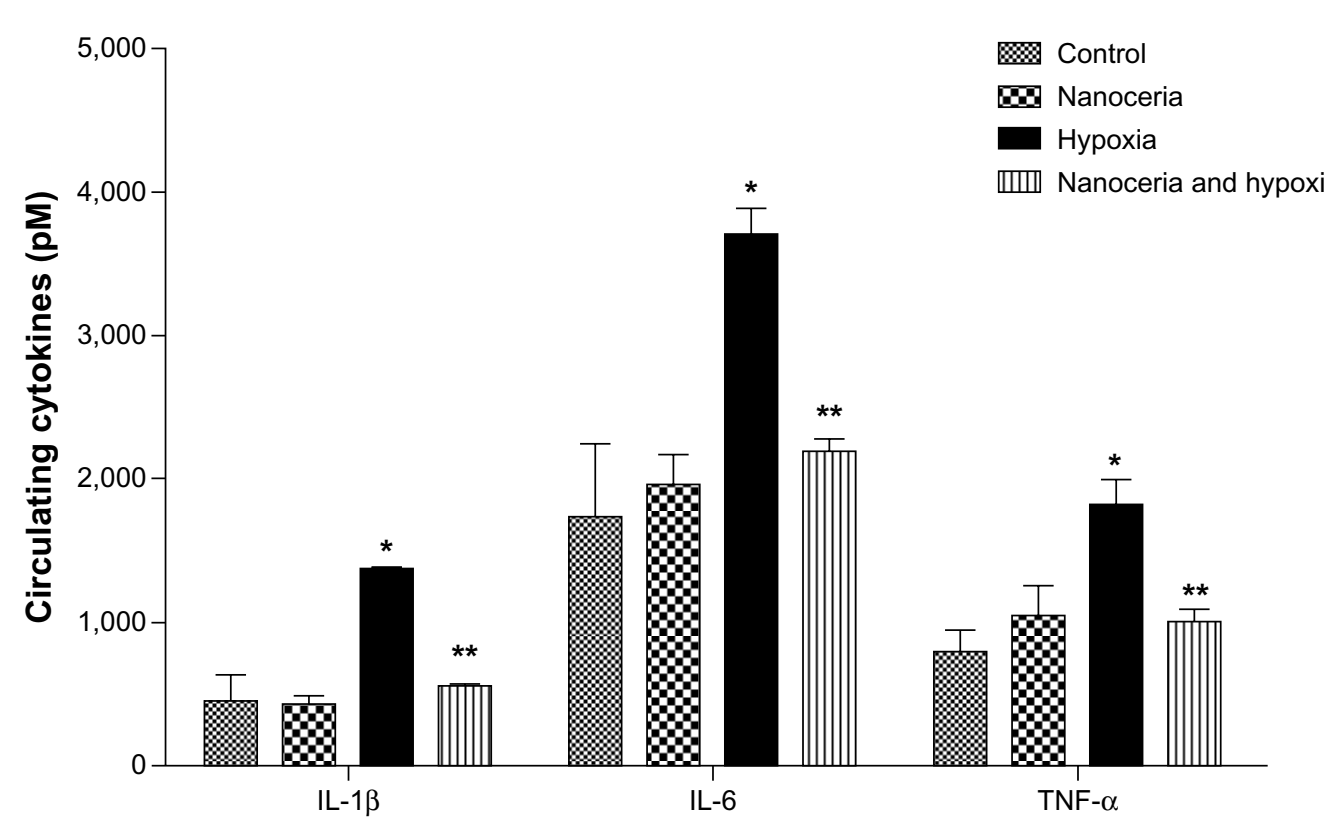

Figure 3 Estimation of circulating cytokines in plasma. Concentrations of interleukin (IL)-I $\beta$ (control [C]: 454.50 \pm I76.00, nanoceria treated [T]: 425.70 \pm 62.60 , hypoxia

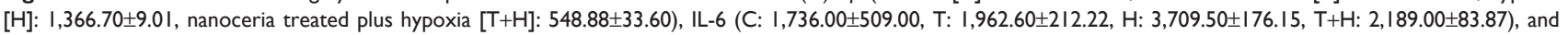
tumor necrosis factor (TNF)- $\alpha$ (C: $797.39 \pm 149.70, \mathrm{~T}: 1,047.15 \pm 12.20, \mathrm{H}: 1,813.20 \pm 76.10, \mathrm{~T}+\mathrm{H}: 1,005.70 \pm 83.80$ ) were elevated during hypoxia, whereas animals administered nanoceria showed no such increases. The concentration of circulating cytokines in nanoceria-treated and hypoxia-exposed animals ( $\mathrm{n}=10$ ) was significantly lower than that in hypoxic animals.

Notes: $* P<0.05 ; * * P<0.01$.

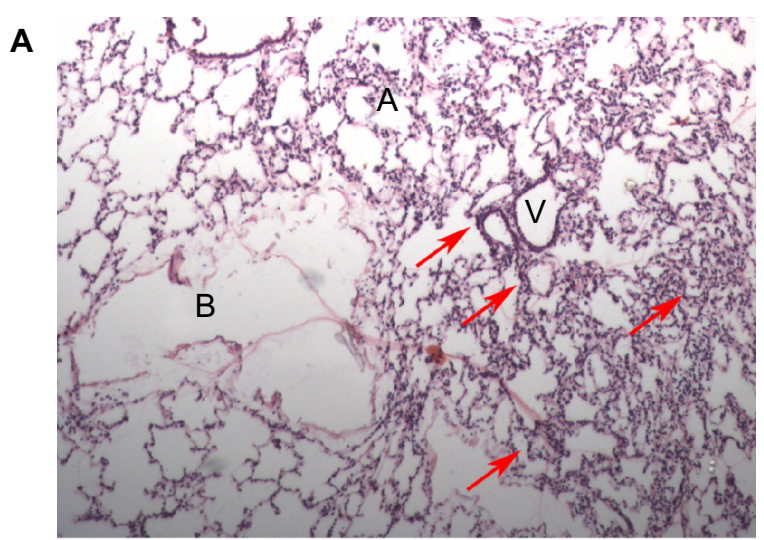

$\mathbf{B}$

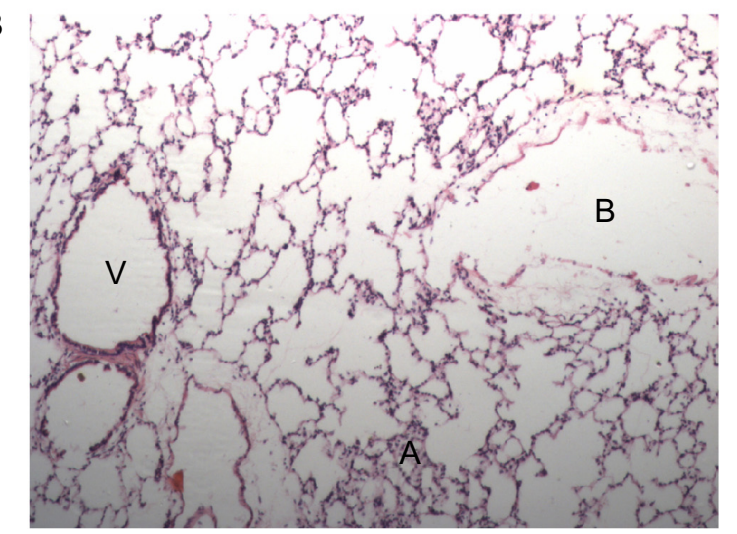

Figure 4 Histopathological examination of rat lung tissue for tissue inflammation. Photomicrographs of hematoxylin and eosin-stained lung sections (20x): (A) hypoxic lung sections showed localized neutrophil infiltration and inflammation (indicated by arrows); (B) nanoceria-deposited lungs did not show any sign of inflammation. Abbreviations: $\mathrm{A}$, alveoli; $\mathrm{B}$, bronchioles; $\mathrm{V}$, blood vessels. nanoceria-supplemented hypoxic lungs. There was no significant difference in 3-NT levels between normoxic and nanoceria-supplemented lungs (Figure 5F). These results suggest that nanoceria accumulation in rodent lung ameliorates hypobaric hypoxia-induced oxidative stress.

\section{Discussion}

The lung is a highly specialized organ with the primary function of maintaining adequate oxygenation in the organism. Decreased partial pressure of inspired oxygen during hypobaric hypoxia, as well as oxygen-limiting conditions during pathological hypoxia, affects lung functions and body oxygenation. ${ }^{21}$ These conditions alter the lung redox balance by promoting RONS generation, which subsequently damages cellular macromolecules like lipids, DNA, and protein. ${ }^{24,28}$ Increasing evidence suggests that lung oxidative stress is associated with life-threatening respiratory, inflammatory, and vascular disorders. ${ }^{20,37}$ Therefore, we explored the regenerative antioxidant properties of nanoceria in rat lungs after brief exposure to hypobaric hypoxia.

In our study, we successfully demonstrated that repeated ip injection of a low micromolar concentration of engineered spherical nanoceria with a particle size of 7-10 nm results in nanoceria accumulation in the lung without any adverse effects. ${ }^{6}$ Electron microscopy of lung sections along with SAED analysis verified the presence of nanoceria in the 

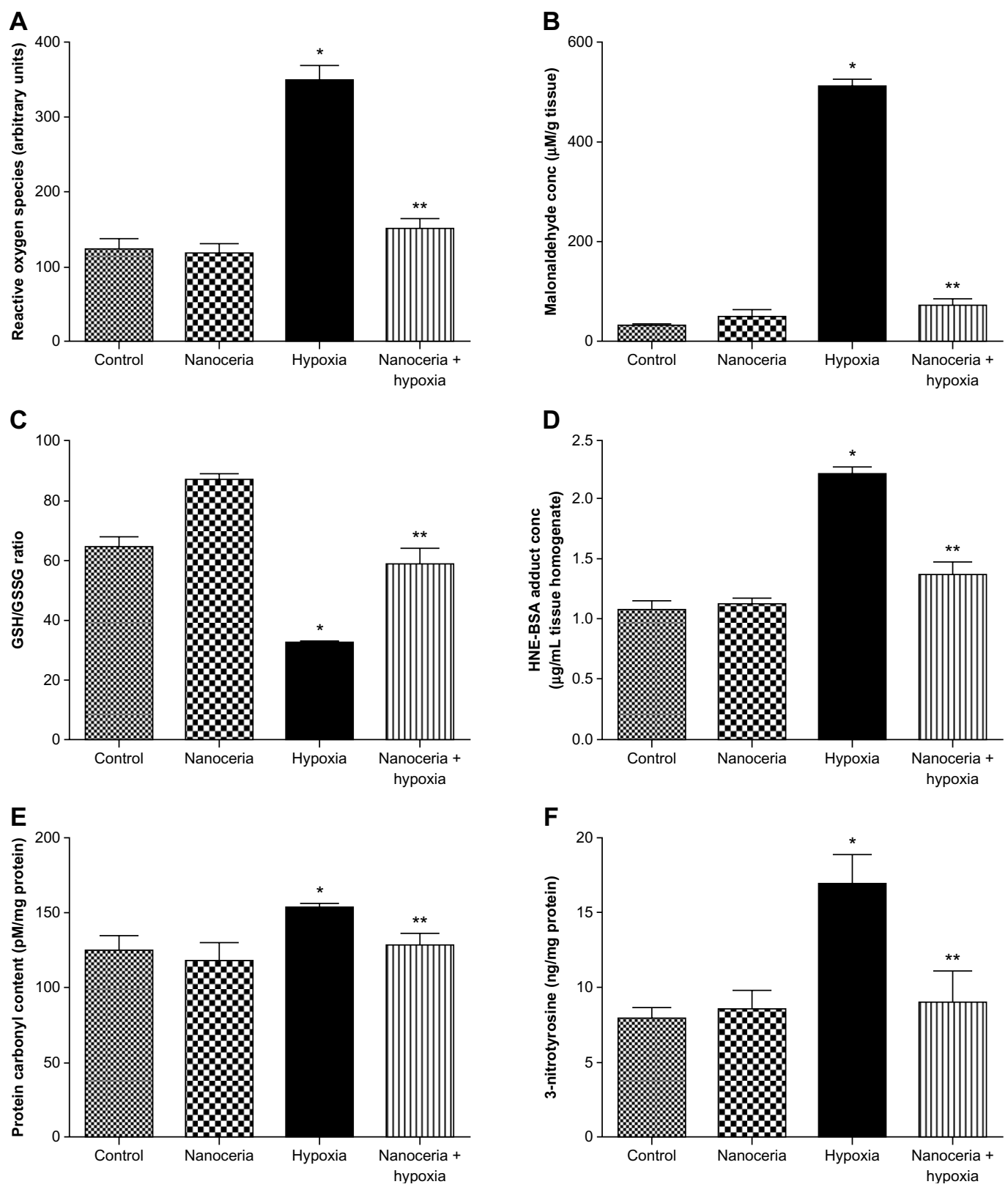

Figure 5 Estimation of oxidative stress indicators in lung tissue homogenate. (A) Hypoxic lung tissue showed an increase in the radical generation, while nanoceria-deposited lung exposed to hypoxia did not show any increase, as compared with the control. Nanoceria alone did not cause any increase in free radicals (control [C]: I23.8 \pm I3.4, nanoceria treated $[\mathrm{T}]$ : I I9.3 \pm II.2, hypoxia [H]: 350.2 \pm I9.2, nanoceria treated plus hypoxia $[\mathrm{T}+\mathrm{H}]$ : I50.2 \pm I3.2). (B) Hypoxic lung showed an increase in lipid peroxidation, while nanoceria-deposited lung exposed to hypoxia did not show any increase in malonaldehyde levels (C: $30.9 \pm 5.3, \mathrm{~T}: 5 \mathrm{I} .2 \pm \mathrm{II} .9, \mathrm{H}: 5 \mathrm{I} 2.3 \pm \mathrm{I} 3.3, \mathrm{~T}+\mathrm{H}: 72.2 \pm \mathrm{II} .9)$. (C) The glutathione (GSH)/glutathione disulfide (GSSG) ratio was reduced in hypoxic lungs, while nanoceria-deposited lungs exposed to hypoxia had a GSH/GSSG ratio equivalent to that of the control. The GSH/GSSG ratio was increased in nanoceria alone (C: $65.0 \pm 2.8, \mathrm{~T}: 70.3 \pm$ I I.6, H: $32.4 \pm 0.4, \mathrm{~T}+\mathrm{H}$ : $58.9 \pm 4.8$ ). (D) In hypoxic lungs, 4-hydroxynoneal

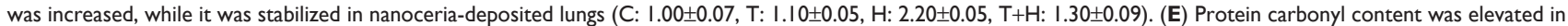

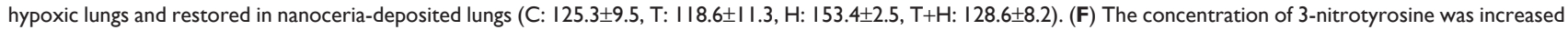
during hypoxia, while no significant elevation was observed in nanoceria-deposited lungs exposed to hypoxia (C: 1.07 $\pm 0.07, \mathrm{~T}$ : I.10 $\pm 0.05, \mathrm{H}: 2.20 \pm 0.05, \mathrm{~T}+\mathrm{H}$ : $1.30 \pm 0.09)$. Notes: All results are the means of three sets of experiments; error bars represent the standard error of the mean $(n=10)$. $* P<0.05$; $* * P<0.01$. Abbreviations: HNE, 4-hydroxynoneal; BSA, bovine serum albumin.

lungs after 5 weeks of dosage. Histological examinations of lung sections revealed no alterations in tissue morphology as well as no visible signs of inflammation. Further, no significant elevation in the levels of plasma inflammatory cytokines IL-1 $\beta$, IL- 6 , or TNF- $\alpha$ was observed, supporting the noncytotoxic properties of nanoceria. The cytotoxicity of nanoceria in lung tissue remains controversial, as isolated studies have reported nanoceria-induced pulmonary inflammation. ${ }^{38,39}$ These studies were performed with commercially synthesized nanoceria used in the petrochemical industry with nanoceria of particle sizes greater than $20 \mathrm{~nm}$. However, the biopersistence and organ deposition of nanoceria are 
favored when particles are of smaller size ${ }^{6}$ The present study, using nanoceria with particle sizes of 7-10 nm, provides the first comprehensive evidence for the noncytotoxic activities of nanoceria in lung tissue.

The nanoceria used in this study scavenged hypoxiainduced enhanced RONS produced in lungs. We observed significantly lower levels of ROS, lipid peroxides, and oxidized proteins in nanoceria-deposited lungs than in hypoxic lungs. Interestingly, we also observed significantly lower levels of 3-NT in nanoceria-deposited lungs than in hypoxic lungs. Nitric oxide (NO) rapidly reacts with the radical superoxide formed during hypoxia to form peroxynitrite. At physiological $\mathrm{pH}$ and in the presence of transition metals, peroxynitrite undergoes cleavage to form the hydroxyl anion and nitronium ion, which further nitrate protein tyrosine residues. Thus, peroxynitrite is a strong oxidant as well as nitrating agent that can induce inflammation and is involved in the pathology of several inflammatory human diseases.

Along with reduced 3-NT levels, we also observed a significant reduction of circulatory inflammatory cytokine levels. Moreover, no visible lung inflammation was seen in nanoceria-treated hypoxia-exposed rats, whereas hypoxia alone induced lung inflammation. Nanoceria-mediated lower 3-NT levels and associated inflammation have been reported to confer neuroprotection during ischemia ${ }^{15}$ and cardioprotection in a transgenic murine model of cardiomyopathy. ${ }^{40}$ In corroboration with these findings, our results demonstrating the antioxidant properties of nanoceria in hypoxic lungs suggest that the antioxidant property of nanoceria is partly mediated by their ability to reduce in vivo protein nitration.

Recent investigations have reported that the presence of large fraction of $\mathrm{Ce}^{3+}$ enables nanoceria to mimic the activity of superoxide dismutase, the enzyme that catalyzes the dismutation of the superoxide radical anion $\left(\mathrm{O}_{2}^{-}\right)$in living cells, and the presence of a large fraction of $\mathrm{Ce}^{4+}$ results in catalase-like activity with the ability to decompose hydrogen peroxide to oxygen and water. Superoxide anion is the one-electron reduction product of oxygen, the precursor for most ROS, and is a mediator in the oxidative chain reaction. In addition, superoxide anion may react with NO to form a powerful oxidant, peroxynitrite. The limited availability of molecular oxygen as terminal electron acceptor during hypoxia promotes the leakage of electrons from the mitochondrial respiratory chain and subsequent superoxide formation. Hence, the dismutation of superoxide to hydrogen peroxide by the $\mathrm{Ce}^{3+}$ fraction (superoxide dismutase activity) and subsequent reduction to water by $\mathrm{Ce}^{4+}$ fraction (catalase activity) limit hypoxia-induced oxidative damage. Moreover, the combination of these two redox reactions also allows the continuous regeneration of nanoceria antioxidant activity, potentially quenching intracellular ROS by a self-regenerating mechanism.

Our current findings demonstrate that repeated ip injection of nanoceria results in the deposition of nanoceria in lungs and quenches hypoxia-induced noxious RONS. Since time exposure to nanoparticles is supposedly a critical factor for nanoceria efficiency, we used repeated dosing to ensure lung availability. However, further studies are needed to understand the effect of single dosing with higher concentrations of nanoceria. Since differences in physiochemical parameters like synthesis techniques, size, shape, and charge are critical for nanoceria cellular uptake, localization, and beneficial effects, further studies are required to address the biological effects of nanoceria.

\section{Conclusion}

Our study provides comprehensive evidence for the lung protective efficacy of nanoceria during biological oxidative stress. Injecting rats with spherical nanoceria with a particle diameter of 7-10 nm, we could successfully demonstrate that the engineered nanoceria deposits in the lung, is noninflammatory, and protects the lung from hypobaric hypoxia-induced oxidative stress. In particular, nanoceria reduced ROS formation, lipid peroxidation, and prevented oxidative protein modifications like protein carbonyl and peroxynitrite formation. These results suggest the therapeutic potential of engineered nanoceria in preventing lung oxidative damage in clinical settings as well as their potential for use as high-altitude nanomedicine.

\section{Acknowledgments}

This study was supported by the Defence Research and Development Organization (DIP-254). The authors would like to acknowledge Dr Raj Sharma, Delhi University, for his technical help. AA is a recipient of a Senior Research Fellowship from the Council of Scientific and Industrial Research, Government of India.

\section{Disclosure}

The authors declare that there are no conflicts of interest in this work.

\section{References}

1. Karakoti AS, Monteiro-Riviere NA, Aggarwal R, et al. Nanoceria as antioxidant: synthesis and biomedical applications. JOM (1989). 2008; 60(3):33-37.

2. Heckert EG, Karakoti AS, Seal S, Self WT. The role of cerium redox state in the SOD mimetic activity of nanoceria. Biomaterials. 2008;29(18): 2705-2709. 
3. Pirmohamed T, Dowding JM, Singh S, et al. Nanoceria exhibit redox state-dependent catalase mimetic activity. Chem Commun (Camb). 2010;46(16):2736-2738.

4. Hirst SM, Karakoti A, Singh S, et al. Bio-distribution and in vivo antioxidant effects of cerium oxide nanoparticles in mice. Environ Toxicol. 2013;28(2):107-118.

5. Yokel RA, Au TC, MacPhail R, et al. Distribution, elimination, and biopersistence to 90 days of a systemically introduced $30 \mathrm{~nm}$ ceriaengineered nanomaterial in rats. Toxicol Sci. 2012;127(1):256-268.

6. Yokel RA, Tseng MT, Dan M, et al. Biodistribution and biopersistence of ceria engineered nanomaterials: size dependence. Nanomedicine. 2013;9(3):398-407.

7. Cai X, Sezate SA, Seal S, McGinnis JF. Sustained protection against photoreceptor degeneration in tubby mice by intravitreal injection of nanoceria. Biomaterials. 2012;33(34):8771-8781.

8. Das S, Singh S, Dowding JM, et al. The induction of angiogenesis by cerium oxide nanoparticles through the modulation of oxygen in intracellular environments. Biomaterials. 2012;33(31):7746-7755.

9. Chaudhury K, Babu KN, Singh AK, Das S, Kumar A, Seal S. Mitigation of endometriosis using regenerative cerium oxide nanoparticles. Nanomedicine. 2013;9(3):439-448.

10. Amin KA, Hassan MS, Awad el-ST, Hashem KS. The protective effects of cerium oxide nanoparticles against hepatic oxidative damage induced by monocrotaline. In J Nanomedicine. 2011;6:143-149.

11. Pagliari F, Mandoli C, Forte G, et al. Cerium oxide nanoparticles protect cardiac progenitor cells from oxidative stress. ACS Nano. 2012;6(5): 3767-3775.

12. Tsai YY, Oca-Cossio J, Agering K, et al. Novel synthesis of cerium oxide nanoparticles for free radical scavenging. Nanomedicine (Lond). 2007;2(3):325-332.

13. Colon J, Hsieh N, Ferguson A, et al. Cerium oxide nanoparticles protect gastrointestinal epithelium from radiation-induced damage by reduction of reactive oxygen species and upregulation of superoxide dismutase 2 . Nanomedicine. 2010;6(5):698-705.

14. Chen J, Patil S, Seal S, McGinnis JF. Rare earth nanoparticles prevent retinal degeneration induced by intracellular peroxides. Nat Nanotechnol. 2006;1(2):142-150.

15. Estevez AY, Pritchard S, Harper K, et al. Neuroprotective mechanisms of cerium oxide nanoparticles in a mouse hippocampal brain slice model of ischemia. Free Radic Biol Med. 2011;51(6):1155-1163.

16. Chigurupati S, Mughal MR, Okun E, et al. Effects of cerium oxide nanoparticles on the growth of keratinocytes, fibroblasts and vascular endothelial cells in cutaneous wound healing. Biomaterials. 2013;34(9): 2194-2201.

17. Kong L, Cai X, Zhou X, et al. Nanoceria extend photoreceptor cell lifespan in tubby mice by modulation of apoptosis/survival signaling pathways. Neurobiol Dis. 2011;42(3):514-523.

18. Hirst SM, Karakoti AS, Tyler RD, Sriranganathan N, Seal S, Reilly CM. Anti-inflammatory properties of cerium oxide nanoparticles. Small. 2009;5(24):2848-2856.

19. Voelkel NF, McMurtry IF, Reeves JT. Hypoxia impairs vasodilation in the lung. J Clin Invest. 1981;67(1):238-246.

20. Bärtsch P, Straub PW, Haeberli A. Hypobaric hypoxia. Lancet. 2001; 357(9260):955-956.
21. Sylvester JT, Shimoda LA, Aaronson PI, Ward JP. Hypoxic pulmonary vasoconstriction. Physiol Rev. 2012;92(1):367-520.

22. Turrens JF. Mitochondrial formation of reactive oxygen species. J Physiol. 2003;552(Pt 2):335-344.

23. Winterbourn CC. Reconciling the chemistry and biology of reactive oxygen species. Nat Chem Biol. 2008;4(5):278-286.

24. Dosek A, Ohno H, Acs Z, Taylor AW, Radak Z. High altitude and oxidative stress. Respir Physiol Neurobiol. 2007;158(2-3):128-131.

25. Singh M, Arya A, Kumar R, Bhargava K, Sethy NK. Dietary nitrite attenuates oxidative stress and activates antioxidant genes in rat heart during hypobaric hypoxia. Nitric Oxide. 2012;26(1):61-73.

26. Hultgren HN. High-altitude pulmonary edema: current concepts. Ann Rev Med. 1996;47:267-284.

27. Tuder RM, Petrache I. Pathogenesis of chronic obstructive pulmonary disease. J Clin Invest. 2012;122(8):2749-2755.

28. Rosanna DP, Salvatore C. Reactive oxygen species, inflammation, and lung diseases. Curr Pharm Des. 2012;18(26):3889-3900.

29. Halliwell B. Free radicals and antioxidants: updating a personal view. Nutr Rev. 2012;70(5):257-265.

30. Tang SY, Halliwell B. Medicinal plants and antioxidants: what do we learn from cell culture and Caenorhabditis elegans studies? Biochem Biophys Res Commun. 2010;394(1):1-5.

31. Halliwell B. Plasma antioxidants: health benefits of eating chocolate? Nature. 2003;426(6968):787; discussion 788.

32. Das M, Patil S, Bhargava N, Kang JF, et al. Auto-catalytic ceria nanoparticles offer neuroprotection to adult rat spinal cord neurons. Biomaterials. 2007;28(10):1918-1925.

33. Best TM, Fiebig R, Corr DT, Brickson S, Ji L. Free radical activity, antioxidant enzyme, and glutathione changes with muscle stretch injury in rabbits. J Appl Physiol (1985). 1999;87(1):74-82.

34. Ohkawa H, Ohishi N, Yagi K. Assay for lipid peroxides in animal tissues by thiobarbituric acid reaction. Anal Biochem. 1979;95(2): 351-358.

35. Hardas SS, Butterfield DA, Sultana R, et al. Brain distribution and toxicological evaluation of a systemically delivered engineered nanoscale ceria. Toxicol Sci. 2010;116(2):562-576.

36. Nathan C, Cunningham-Bussel A. Beyond oxidative stress: an immunologist's guide to reactive oxygen species. Nat Rev Immunol. 2013;13(5):349-361.

37. Faiss R, Pialoux V, Sartori C, Faes C, Dériaz O, Millet GP. Ventilation, oxidative stress, and nitric oxide in hypobaric versus normobaric hypoxia. Med Sci Sports Exerc. 2013;45(2):253-260.

38. Ma JY, Zhao H, Mercer RR, et al. Cerium oxide nanoparticle-induced pulmonary inflammation and alveolar macrophage functional change in rats. Nanotoxicology. 2011;5(3):312-325.

39. Cho WS, Duffin R, Poland CA, et al. Metal oxide nanoparticles induce unique inflammatory footprints in the lung: important implications for nanoparticle testing. Environ Health Perspect. 2010;118(12): 1699-1706.

40. Jinali N, Asim A, Linda MR, Xihai W, Pappachan EK. Cardioprotective effcets of cerium oxide nanoparticles in a transgenic murine model of cardiomyopathy. Cardiovasc Res. 2007;73(3):549-559. 


\section{Supplementary material}
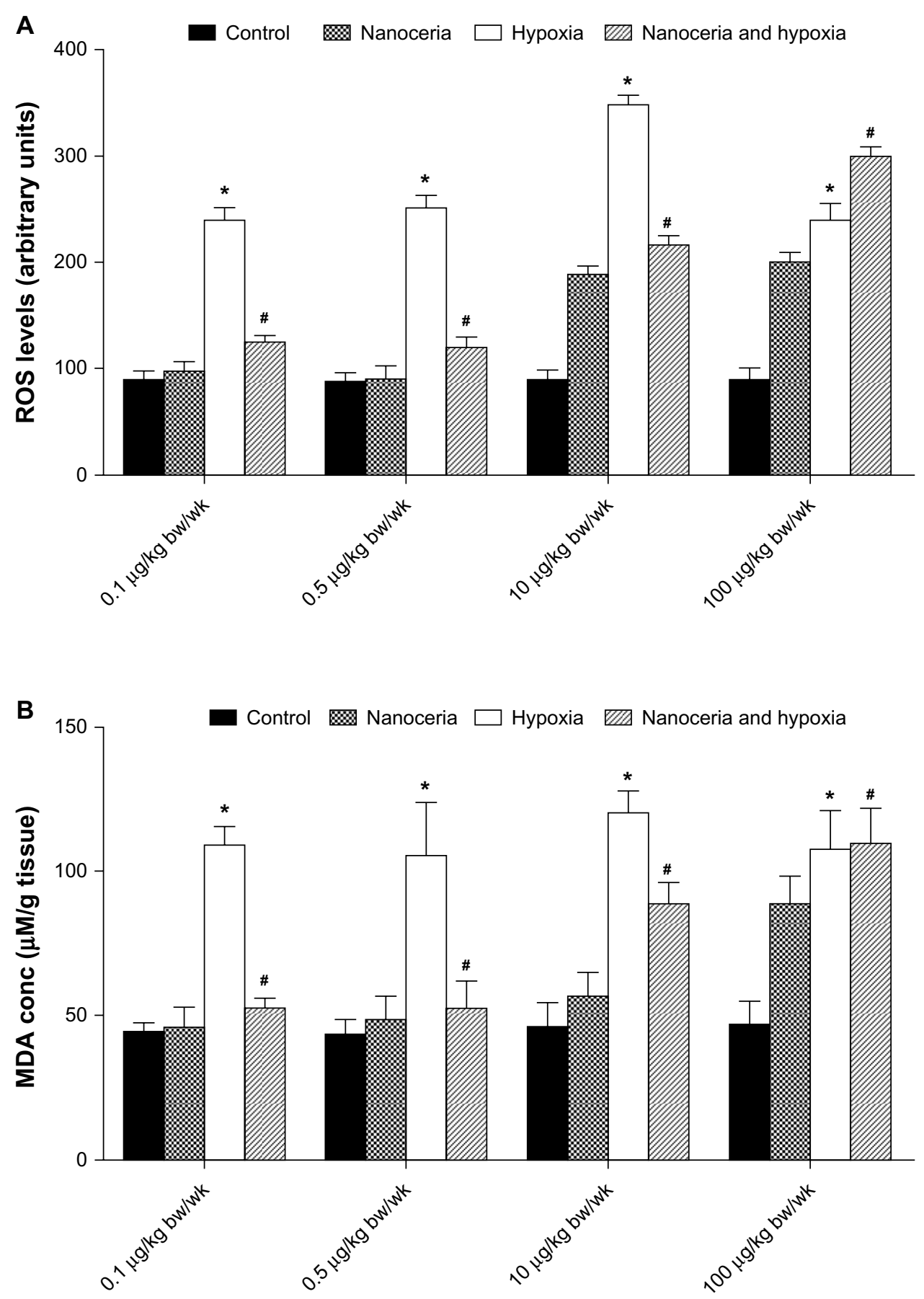

Figure SI Optimization of nanoceria dose for optimal reactive oxygen species (ROS) scavenging and antioxidant activity. (A) ROS in rat lung tissue homogenate after various dosages of nanoceria for 5 weeks. (B) Malonaldehyde (MDA) levels in rat lung tissue homogenate after various dosages of nanoceria for 5 weeks. A dosage of $0.5 \mu \mathrm{g} / \mathrm{kg}$ body weight of nanoceria was optimal for their radical scavenging activity.

Notes: Actual datapoints are presented in Tables SI and S2. Data are presented as mean \pm standard error of the mean. ${ }^{* P}<0.05 ;{ }^{\# P}<0.01$.

Abbreviations: bw, body weight; wk, week. 

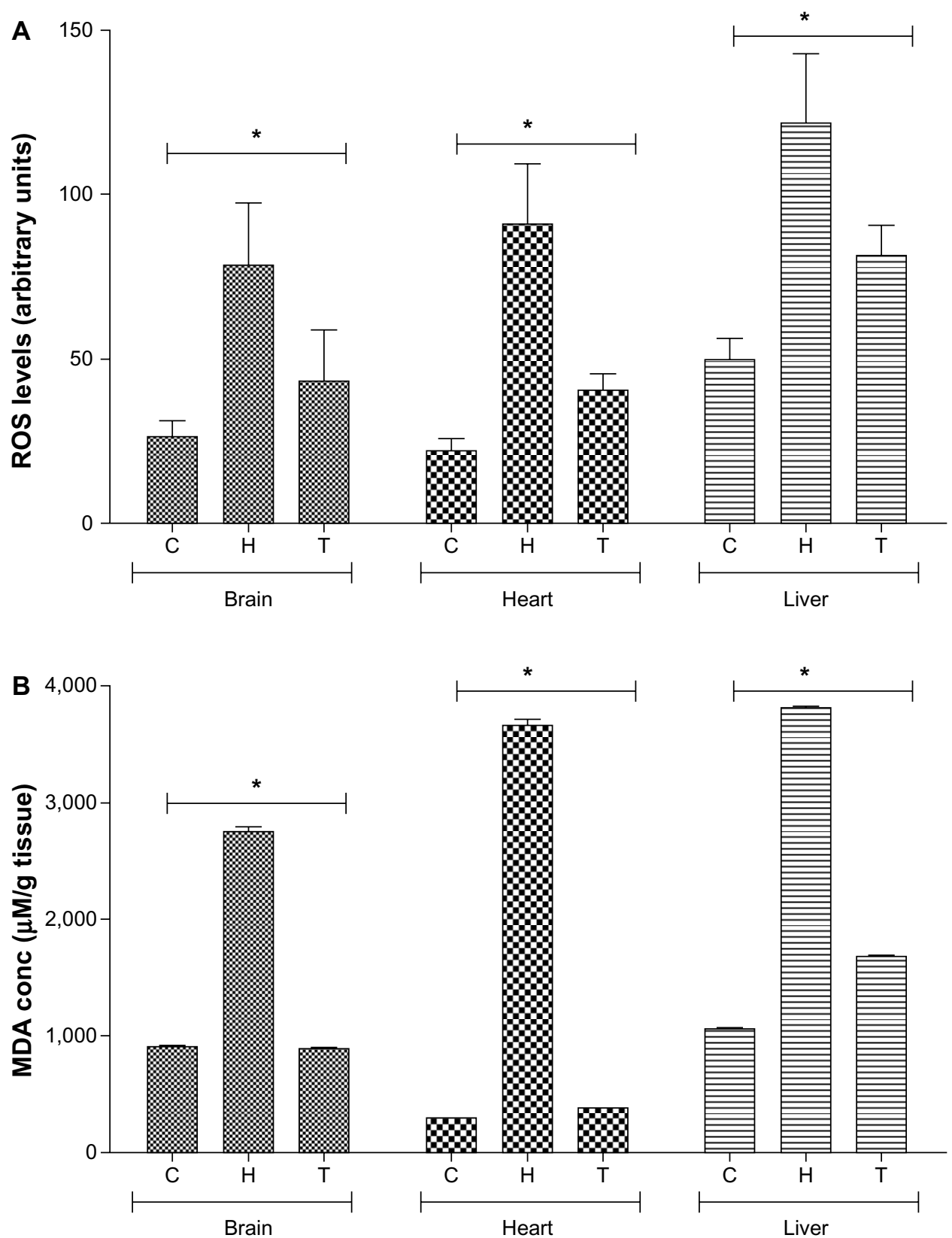

Figure S2 The effect of nanoceria on other vital organs. (A) Estimation of reactive oxygen species (ROS) estimation in the brain, heart, and liver. (B) Malonaldehyde (MDA) estimation in the brain, heart, and liver.

Notes: Data presented as mean \pm standard deviation. $* P<0.05$.

Abbreviations: $\mathrm{C}$, control; $\mathrm{H}$, hypoxia; $\mathrm{T}$, nanoceria and hypoxia. 

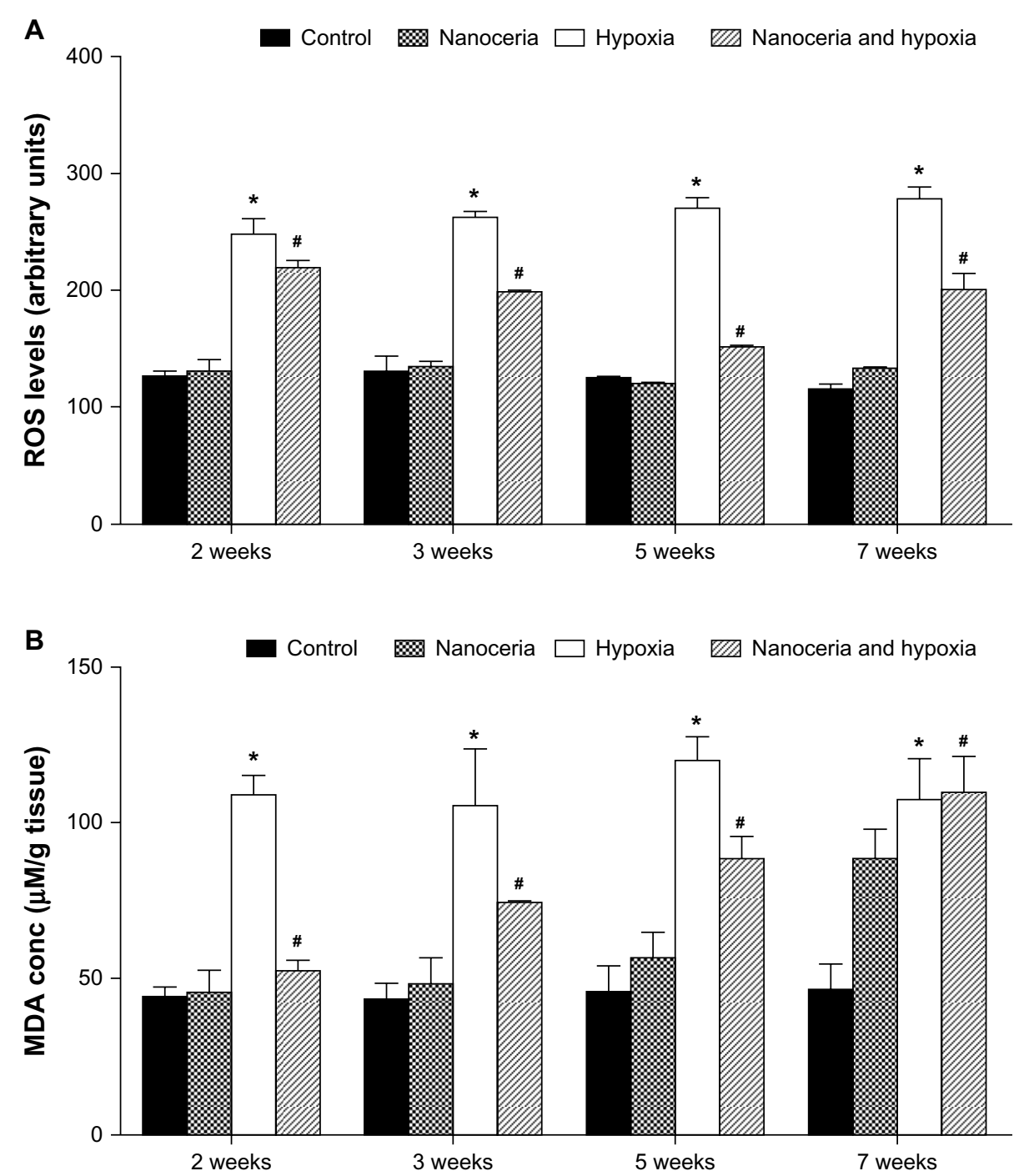

Figure S3 Optimization of nanoceria dose duration for optimal reactive oxygen species (ROS) scavenging and antioxidant activity. (A) ROS in lung tissue homogenate postintraperitoneal dose administration in rats for 2, 3, 5, or 7 weeks. (B) Malonaldehyde (MDA) levels rat lung tissue homogenate after various dosages of nanoceria for 2, 3, 5, or 7 weeks. A 5-week dose of the optimized concentration showed optimal ROS scavenging potential.

Notes: Data presented as mean \pm standard error of the mean. ${ }^{*} P<0.05 ;{ }^{*} P<0.01$.

Table SI Estimation of ROS levels with different nanoceria dosages under hypoxia

\begin{tabular}{lllllllll}
\hline Dosage, $\mu \mathrm{g} / \mathrm{kg}$ bw/wk & $\begin{array}{l}\text { Control } \\
\text { Mean }\end{array}$ & SEM & $\begin{array}{l}\text { Nanoceria } \\
\text { Mean }\end{array}$ & SEM & $\begin{array}{l}\text { Hypoxia } \\
\text { Mean }\end{array}$ & SEM & $\begin{array}{l}\text { Nanoceria and hypoxia } \\
\text { Mean }\end{array}$ & SEM \\
\hline 0.1 & 89.2320 & 8.420000 & 98.322300 & 8.323000 & 239.430000 & 12.342340 & 125.234200 & 6.310000 \\
0.5 & 87.2392 & 9.424000 & 90.324000 & 12.323000 & 250.342000 & 12.323000 & 120.133000 & 9.323000 \\
10.0 & 90.2320 & 8.324000 & 189.093000 & 7.424000 & 348.232000 & 8.432400 & 216.343000 & 8.434000 \\
100.0 & 88.2324 & 12.494000 & 200.343000 & 9.432400 & 239.232000 & 16.323000 & 300.232300 & 8.433400 \\
\hline
\end{tabular}

Abbreviations: bw, body weight; wk, week; SEM, standard error of the mean.

Table S2 MDA concentrations with different nanoceria dosages under hypoxia

\begin{tabular}{lllllllll}
\hline Dosage, $\mu \mathrm{g} / \mathrm{kg}$ bw/wk & $\begin{array}{l}\text { Control } \\
\text { Mean }\end{array}$ & SEM & $\begin{array}{l}\text { Nanoceria } \\
\text { Mean }\end{array}$ & SEM & $\begin{array}{l}\text { Hypoxia } \\
\text { Mean }\end{array}$ & SEM & $\begin{array}{l}\text { Nanoceria and hypoxia } \\
\text { Mean }\end{array}$ & SEM \\
\hline 0.1 & 44.23200 & 3.131000 & 45.430000 & 7.234200 & 109.123200 & 6.242000 & 52.42432 & 3.54340 \\
0.5 & 43.23440 & 5.232000 & 48.232400 & 8.324000 & 105.343000 & 18.323400 & 52.43400 & 9.43400 \\
10.0 & 45.54300 & 8.422000 & 56.343000 & 8.424000 & 120.121000 & 7.324200 & 88.43240 & 7.43242 \\
100.0 & 46.43300 & 8.240000 & 88.432400 & 9.422000 & 107.430000 & 13.131000 & 109.42240 & 12.13230 \\
\hline
\end{tabular}

Abbreviations: bw, body weight; wk, week; SEM, standard error of the mean; MDA, malonaldehyde. 


\section{Publish your work in this journal}

The International Journal of Nanomedicine is an international, peerreviewed journal focusing on the application of nanotechnology in diagnostics, therapeutics, and drug delivery systems throughout the biomedical field. This journal is indexed on PubMed Central, MedLine, CAS, SciSearch ${ }^{\circledR}$, Current Contents ${ }^{\circledR} /$ Clinical Medicine,

Journal Citation Reports/Science Edition, EMBase, Scopus and the Elsevier Bibliographic databases. The manuscript management system is completely online and includes a very quick and fair peer-review system, which is all easy to use. Visit http://www.dovepress.com/ testimonials.php to read real quotes from published authors.

Submit your manuscript here: http://www.dovepress.com/international-journal-of-nanomedicine-journal 